\title{
Portaenxertos e métodos de enxertia na produção de mudas de Atemoieira (Annona squamosa L. x Annona cherimola Mill.)
}

\section{Rootstocks and grafting methods for Atemoya (Annona squamosa $\mathbf{L}$. x Annona cherimoya Mill.) plants}

\author{
Grazianny Andrade Leite ${ }^{1 *}$; Vander Mendonça ${ }^{2}$; \\ Luciana Freitas de Medeiros Mendonça'; \\ Lydio Luciano de Gois Ribeiro Dantas 3 ; Poliana Samara de Castro Freitas Cunha ${ }^{4}$
}

Resumo

\begin{abstract}
Este experimento teve por finalidade avaliar a propagação por enxertia de atemoieira sobre dois portaenxertos (Annona squamosa L. e Annona glabra L.). O delineamento experimental utilizado foi o de blocos casualizados em esquema fatorial $2 \times 5$, sendo dois portaenxertos e cinco métodos de enxertia em 5 blocos e 10 plantas por parcela, totalizando 500 plantas. Foram avaliadas aos 60 dias após a enxertia as variáveis pegamento dos enxertos (\%), enxertos brotados (\%), enxertos dormentes $(\%)$ e enxertos vivos (\%). Também foram avaliados comprimento da parte aérea $(\mathrm{cm})$, diâmetro do colo $(\mathrm{mm})$, comprimento do sistema radicular $(\mathrm{cm})$, número de folhas (unidade/planta), massa seca do sistema radicular ( $\mathrm{g} / \mathrm{planta}$ ), massa seca da parte aérea ( $\mathrm{g} / \mathrm{planta}$ ), massa seca total ( $\mathrm{g} / \mathrm{planta}$ ) e relação massa seca da parte aérea e massa seca do sistema radicular. Os dados referentes ao diâmetro dos portaenxertos e as médias das características do enxerto foram submetidos à análise de variância e as médias comparadas pelo teste de Scott-Knott, ao nível de $5 \%$ de probabilidade. No tocante às características de percentagem de pegamento, enxertos vivos, brotados e dormentes, os dados foram transformados em $\sqrt{(\mathrm{x}+1)}$ para análise de variância, sendo as médias comparadas pelo teste de ScottKnott, ao nível de $5 \%$ de probabilidade. A atemoieira 'Gefner' pode ser enxertada nos portaenxertos Annona glabra L. e Annona squamosa L. pelo método de garfagem fenda cheia. Os métodos de enxertia inglês simples e inglês complicado podem ser utilizados se a atemoieira 'Gefner' for enxertada no portaenxerto Annona squamosa L. O método de enxertia por borbulhia não é eficiente para a produção de mudas de atemoieira 'Gefner'.
\end{abstract}

Palavras-chave: Atemóia, propagação vegetativa, araticum-do-brejo, pinha

\begin{abstract}
This experiment aimed to evaluate the production of atemoya nursery plants grafted on two rootstocks (Annona squamosa L. and Annona glabra L.). The experimental design was a 2 x 5 factorial being two rootstocks and five methods of grafting, with five randomized blocks and ten plants per plot, totaling 500 plants. The variables evaluated at 60 days after grafting were budding efficiency (\%), shooting grafts (\%) dormant grafts (\%) and living grafts (\%). It was also evaluated the shoot length $(\mathrm{cm})$, stem diameter (mm), root system length $(\mathrm{cm})$, number of leaves (unit /plant), dry root mass (g/plant), shoot
\end{abstract}

\footnotetext{
${ }^{1}$ Eng $^{\text {as }}$ Agr $^{\text {as }}$, Mestre em Fitotecnia, Discente de Doutorado do Programa de Pós Graduação em Fitotecnia da Universidade Federal Rural do Semi-Árido, UFERSA, Mossoró, RN. E-mail: graziannyandrade@yahoo.com.br; lucisfreitas@hotmail.com

${ }^{2}$ Eng $^{\circ}$ Agr $^{\circ}$, Prof. Dr. Adjunto do Dept ${ }^{\circ}$ de Ciências Vegetais, UFERSA, Mossoró, RN. E-mail: vander@ufersa.edu.br

${ }^{3}$ Eng $^{\circ}$ Agro $^{\circ}$, Discente de Mestrado do Programa de Pós Graduação em Fitotecnia da Universidade Federal do Ceará, UFC, Fortaleza, CE. E-mail: lydio_dantas@hotmail.com

${ }^{4}$ Eng $^{\mathrm{a}}$ Agr ${ }^{\mathrm{a}}$, M.e em Fitotecnia da UFERSA, Mossoró, RN. E-mail: polianasamar@hotmail.com

* Autor para correspondência
} 
dry mass ( $\mathrm{g} /$ plant), total dry mass $(\mathrm{g} /$ plant), length seedling $(\mathrm{cm})$ and shoot: root system dry mass ratio. Data regarding diameter of the rootstock and means of graft characteristics were submitted to analysis of variance. For the characteristics of percentage of grafting effectiveness, living grafts, shooting and dormant grafts, data were transformed in $\sqrt{(\mathrm{x}+1)}$ for analysis of variance, all means compared by Scott-Knott test, at 5\% probability. Atemoya 'Gefner' can be grafted on rootstocks Annona glabra L. and Annona squamosa L. by cleft grafting method. The grafting whip and double whip can be used to atemoya 'Gefner' if grafting onto rootstock Annona squamosa L. Budding grafting method is not efficient for the production of atemoya 'Gefner' plants.

Key words: Atemoya, vegetative propagation, swamp apple, sweetsop

\section{Introdução}

A atemoieira é um híbrido interespecífico entre Annona cherimola Mill. e Annona squamosa L. que deve ter propagação feita assexuadamente para garantir características genéticas de plantas conhecidamente produtivas e para diminuir o período de juvenilidade da planta. Dentre os métodos empregados na produção de mudas de atemóia, utiliza-se a enxertia por borbulhia ou a garfagem (TOKUNAGA, 2000), embora até o momento não tenha sido encontrado portaenxerto com todas as características desejadas (KAVATI, 1992).

A escolha do portaenxerto dá-se pela rusticidade apresentada pelo mesmo, disponibilidade de sementes viáveis, rápido desenvolvimento, compatibilidade com o enxerto, resistência à doenças de solo e indução de boa produtividade. Em geral, com a escolha de portaenxertos mais rústicos que se adaptem melhor às condições fitossanitárias e edafoclimáticas, tenta-se minimizar problemas com brocas-do-tronco e nematóides, além de permitir maior adaptabilidade da copa (LEDO, 1991).

De acordo com Padmaja et al. (1995), a Annona glabra L., espécie frutífera tropical conhecida no Brasil como araticum-do-brejo ou araticum-bravo, tem sido bastante pesquisada como portaenxerto para anonáceas cultivadas. O interesse por este material é devido à tolerância do sistema radicular a condições de excesso de umidade no solo e à indução de nanismo à copa enxertada.

A pinha (Annona squamosa L.), que tem a América Tropical como o seu centro de origem, é uma planta que se desenvolve bem em vários ecossistemas brasileiros, em ambientes de alta e baixa precipitação pluviométrica (ROCHA et al., 2002). A utilização desta planta como portaenxerto proporciona uma formação de plantas compactas, com um rápido crescimento e desenvolvimento em condições de viveiro, além de não apresentar incompatibilidade com diversas cultivares de atemóia (TOKUNAGA, 2000).

Devido ao crescente interesse pela cultura da atemoeira, informações técnicas seguras sobre produção de mudas são de suma importância. As informações que se tem hoje estão restritas a poucas pesquisas, principalmente quando se refere ao portaenxerto. Com isso, objetivou-se testar diferentes métodos de enxertia em atemoieira e dois portaenxertos: a pinha já utilizada como portaenxerto para própria espécie e o araticum-dobrejo, portaenxerto com poucos estudos.

\section{Material e Métodos}

$\mathrm{O}$ experimento foi instalado e conduzido em uma casa de vegetação localizada na Universidade Federal Rural do Semiárido (UFERSA), situada na cidade de Mossoró/RN, no período de fevereiro a novembro de 2010.

As sementes de pinha (Annona squamosa L.) e araticum-do-brejo (Annona glabra L.) foram semeadas em sacos de polietileno preto de 4,5 litros, contendo uma mistura de solo e esterco de curral curtido nas proporções 3:1. Foram adicionados 5 $\mathrm{kg}$ de superfosfato simples $\left(18 \% \mathrm{P}_{2} \mathrm{O}_{5}\right)$ e $1 \mathrm{~kg}$ de cloreto de potássio $\left(60 \% \mathrm{~K}_{2} \mathrm{O}\right)$ por $\mathrm{m}^{3}$ da mistura. $\mathrm{O}$ nitrogênio foi aplicado em cobertura, utilizando- 
se como fonte a uréia $(45 \% \mathrm{~N})$ diluída a $0,3 \%$ e aplicado $20 \mathrm{~mL}$ da solução/saco a partir de 30 dias após a emergência dos portaenxertos.

Os garfos de atemoieira 'Gefner' foram coletados de plantas produtivas, enxertadas e situadas na WG Fruticultura Ltda., no município de Baraúnas/RN em 10 de setembro de 2010. As plantas apresentavam poucas folhas, indicando o final do período de repouso vegetativo. Os ramos foram cortados em seções contendo 8 gemas e envolvidos em toalhas úmidas em caixas de isopor para ser feito o transporte à UFERSA e posterior utilização na enxertia.

As enxertias foram realizadas nos dias 10 e 11 de setembro de 2010 por apenas um enxertador experiente. Durante a enxertia, os garfos apresentavam 4 gemas e comprimento médio de 10 $\mathrm{cm}$, sendo enxertados, em portaenxertos com seis meses de idade, a uma altura de $10 \mathrm{~cm}$ do colo. Após a enxertia as mudas foram colocadas em casa de vegetação com tela de $50 \%$ de sombreamento com irrigação por aspersão. Foram sempre vistoriadas para controle de plantas invasoras, retirada dos ramos do portaenxerto, retirada das inflorescências e observação de pragas e doenças. Não foram necessárias pulverizações com inseticidas, acaricidas ou fungicidas. Após 30 dias da enxertia foram retiradas as fitas plásticas que fixavam a enxertia e feito o corte dos ramos do portaenxerto nos métodos de enxertia fenda lateral e borbulhia.

Foram avaliadas aos 60 dias após a enxertia as variáveis: enxertos vivos (\%), enxertos brotados (\%), enxertos dormentes (\%) e pegamento dos enxertos (\%). Além do número de folhas (unidade/ planta), comprimento da parte aérea $(\mathrm{cm})$, diâmetro do colo ( $\mathrm{mm}$ ), comprimento do sistema radicular (cm), massa seca da parte aérea (g/planta), massa seca do sistema radicular (g/planta), massa seca total (g/planta), comprimento da muda (cm) e relação massa seca da parte aérea e massa seca do sistema radicular.

O delineamento experimental utilizado foi o de blocos casualizados em esquema fatorial $2 \mathrm{x}$ 5, sendo dois portaenxertos (Annona glabra L. e Annona squamosa L.) e cinco métodos de enxertia (garfagem em fenda lateral, no topo a inglês simples, no topo a inglês complicado, no topo em fenda cheia e borbulhia), em 5 repetições de 10 plantas por parcela, totalizando 500 plantas. Os dados referentes ao diâmetro do colo e as médias das características do enxerto foram submetidos à análise de variância. $\mathrm{E}$ as características de percentagem de pegamento, enxertos vivos, brotados e dormentes, os dados foram transformados pela equação $\sqrt{(\mathrm{x}+1)}$ para análise de variância, segundo recomendações de Banzatto e Kronka (1989), sendo as ambas as médias comparadas pelo teste de Scott-Knott, ao nível de 5\% de probabilidade, mas nas tabelas estão apresentados os dados originais.

\section{Resultados e Discussão}

Verificou-se que houve interação significativa entre os portaenxertos e os métodos de enxertia ao nível de $1 \%$ de probabilidade para todas as variáveis analisadas acima citadas. Entretanto, não houve diferença significativa entre os portaenxertos para as variáveis enxertos dormentes e enxertos vivos. De acordo com a análise estatística, verificou-se que houve diferença significativa ao nível de $1 \%$ de probabilidade na interação entre os portaenxertos e os métodos de enxertia para todas as variáveis analisadas, com exceção para o número de folhas que foi significativo ao nível de $5 \%$ de probabilidade e para relação entre a massa seca da parte aérea e a massa seca do sistema radicular que não apresentou diferença significativa. Porém, há diferença significativa ao nível de $1 \%$ de probabilidade para a relação massa seca da parte aérea e massa seca do sistema radicular entre os portaenxertos e entre os métodos de enxertia (Tabelas 1 e 2).

A interação portaenxerto x métodos de enxertia, foi significativa, em ambos os portaenxertos houve maior índice de sobrevivência com o uso do método de enxertia inglês simples e inglês 
complicado (Tabela 1). Porém, o araticum-do-brejo alcançou $100 \%$ de enxertos vivos para o método fenda cheia diferindo do portaenxerto de pinha no mesmo método, onde obteve $85 \%$ de enxertos vivos. O mesmo foi observado para o método fenda lateral, que não houve diferença significativa entre os portaenxertos, conseguindo $80 \%$ e $76,67 \%$ de enxertos vivos para o araticum-do-brejo e pinha, respectivamente.

Tabela 1. Resumo da análise de variância para os índices morfológicos na produção mudas de atemoieira (Annona squamosa x Annona cherimola) em função do portaenxerto (PE) e do método de enxertia (ME). Mossoró (RN), 2011.

\begin{tabular}{cccccc}
\hline \multirow{2}{*}{ FV } & \multirow{2}{*}{ GL } & \multicolumn{4}{c}{ Quadrado médio } \\
\cline { 3 - 6 } & 1 & PEG & BROT & ED & EV \\
\hline PE & $1,12^{*}$ & $6,94^{* *}$ & $2,41^{\text {ns }}$ & $0,94^{\text {ns }}$ \\
ME & 4 & $114,25^{* *}$ & $9,75^{* *}$ & $3,11^{* *}$ & $133,24^{* *}$ \\
PE x ME & 4 & $3,30^{* *}$ & $3,70^{* *}$ & $1,89^{* *}$ & $3,38^{* *}$ \\
Erro & 45 & 0,43 & 0,82 & 0,73 & 0,61 \\
\hline C. V. $(\%)$ & - & 9,16 & 33,43 & 50,58 & 9,87 \\
\hline
\end{tabular}

*- Efeito significativo pelo teste $\mathrm{F}$ ao nível de 5\% de probabilidade;

**- Efeito altamente significativo pelo teste $\mathrm{F}$ ao nível de $1 \%$ de probabilidade; ${ }^{\text {ns }}$ - Efeito não significativo pelo teste $\mathrm{F}$.

Nota: Todos os dados foram transformados em $\sqrt{ }(\mathrm{x}+1)$. PEG-percentagem de pegamento da enxertia; BROT-percentagem de brotação do enxerto; ED-percentagem de enxerto dormente; EV-percentagem de enxerto vivo.

Fonte: Elaboração dos autores.

Tabela 2. Resumo da análise de variância na produção de mudas de atemoieira (Annona squamosa x Annona cherimola) em função do portaenxerto (PE) e do método da enxertia (ME). Mossoró (RN), 2011.

\begin{tabular}{|c|c|c|c|c|c|c|c|c|c|c|}
\hline \multirow[b]{2}{*}{ F. V. } & \multirow[b]{2}{*}{ GL } & \multicolumn{9}{|c|}{ Quadrado médio } \\
\hline & & $\mathrm{DC}$ & CPA & $\mathrm{NF}$ & CSR & $\mathrm{CM}$ & MSPA & MSSR & MST & $\begin{array}{l}\text { MSPA/ } \\
\text { MSSR }\end{array}$ \\
\hline $\mathrm{PE}$ & 1 & $0,53 *$ & $1,85^{* *}$ & $2,88 * *$ & $1,50^{\mathrm{ns}}$ & $3,93^{\mathrm{ns}}$ & $11,33 * *$ & $0,36^{* *}$ & $10,76^{* *}$ & $1,87 * *$ \\
\hline $\mathrm{ME}$ & 4 & $4,47 * *$ & $40,21 * *$ & $20,36^{* *}$ & $48,78^{* *}$ & $95,88 * *$ & $1,79 * *$ & $1,36^{* *}$ & $3,90 * *$ & $0,68 * *$ \\
\hline PE x ME & 4 & $0,48 * *$ & $1,06^{* *}$ & $0,12 *$ & $5,10 * *$ & $6,45^{* *}$ & $0,23 * *$ & $0,21^{* *}$ & $0,63 * *$ & $0,003^{\mathrm{ns}}$ \\
\hline Erro & 45 & 0,09 & 0,2 & 0,04 & 0,79 & 1,07 & 0,05 & 0,04 & 0,1 & 0,02 \\
\hline C. V. $(\%)$ & - & 11,78 & 9 & 5,84 & 15 & 13,62 & 9,47 & 11,57 & 11,43 & 8,61 \\
\hline
\end{tabular}

*- Efeito significativo pelo teste $\mathrm{F}$ ao nível de 5\% de probabilidade; **- Efeito significativo pelo teste $\mathrm{F}$ ao nível de $1 \%$ de probabilidade; ${ }^{\text {ns }}$ - Efeito não significativo pelo teste $\mathrm{F}$.

Nota: DC - diâmetro do colo; CPA - comprimento da parte aérea; NF - número de folha; CSR - comprimento do sistema radicular; MSPA - massa seca da parte aérea; MSSR - massa seca do sistema radicular; MST - massa seca total; CM - comprimento da muda.

Fonte: Elaboração dos autores.

Ledo (1991) obteve resultados semelhantes para enxertia de três variedades de copa de gravioleira e dois métodos de enxertia, com índices de 90,97\% com o método inglês simples e 79,86\% para fenda cheia aos trinta dias após a enxertia. Almeida (2009) analisando a propagação de atemoieira sobre vários portaenxertos de Annonaceae verificou que o enxerto de atemoieira sobre o portaenxerto de araticum-de-terra-fria (Rollinia sp.) apresentou $90 \%$ de sobrevivência para o método inglês simples e 75\% para fenda lateral. Já o portaenxerto biribá apresentou índices de 45,83\% de sobrevivência para o método inglês simples e $24,16 \%$ para fenda lateral. Para fenda lateral, o portaenxerto araticum- 
de-terra-fria alcançou índice de sobrevivência de $75 \%$ e em biribá de $24,16 \%$, aproximadamente o triplo de sobrevivência (ALMEIDA, 2009). Esses trabalhos mencionados anteriormente reafirmam os resultados encontrados no presente estudo, no qual, os métodos de garfagem apresentam maior viabilidade para produção de mudas de atemóia, quando comparados ao método de borbulhia.
A borbulhia foi o único método de enxertia com o qual não se obteve enxertos vivos, como é o caso do araticum-do-brejo como portaenxerto e apenas $13,33 \%$ de EV (enxertos vivos) no portaenxerto de pinha (Tabela 3). Freitas (1997) obteve resultados semelhantes de sobrevivência para enxertia de graviola sobre biribá, com índices menores que $20 \%$.

Tabela 3. Percentagem de enxerto vivo (EV) de mudas de atemoieira (Annona squamosa $\mathrm{x}$ Annona cherimola) em função do portaenxerto e do método de enxertia. Mossoró (RN), 2011.

\begin{tabular}{ccc}
\hline \multirow{2}{*}{ Enxertia* } & \multicolumn{3}{c}{ EV $(\%)$} \\
\cline { 2 - 3 } & Praticum-do-brejo & Portaenxerto \\
\cline { 2 - 3 } B & - & $13,33 \mathrm{c}$ \\
FC & $100,00 \mathrm{a} \mathrm{A}$ & $85,00 \mathrm{~b} \mathrm{~A}$ \\
FL & $80,00 \mathrm{~b} \mathrm{~A}$ & $76,67 \mathrm{~b} \mathrm{~A}$ \\
IC & $90,00 \mathrm{a} \mathrm{A}$ & $93,33 \mathrm{a} \mathrm{A}$ \\
IS & $90,00 \mathrm{a} \mathrm{A}$ & $91,67 \mathrm{a} \mathrm{A}$ \\
\hline
\end{tabular}

Nota: B-borbulhia; FC-fenda cheia; FL-fenda lateral; IC-inglesa complicada; IS-inglesa simples.

*Médias seguidas pela mesma letra, maiúscula na horizontal e minúscula na vertical, não diferem entre si pelo teste de Scott-Knott ao nível de $5 \%$ de probabilidade.

Fonte: Elaboração dos autores.

A porcentagem de pegamento observada quando realizada a borbulhia foi $0 \%$ no araticumdo-brejo e $8,33 \%$ na pinheira, e a porcentagem de brotação de apenas 3,33\% na pinheira e $0 \%$ no araticum-do-brejo. Para este método de enxertia, a maior parte dos enxertos pertenceram as variáveis de porcentagem de gemas dormentes $(1,67 \%$ na pinha e $0 \%$ no araticum-do-brejo) e de enxertos mortos (100\% para araticum-do-brejo e 91,77\% para pinha). Isso se deve, provavelmente, a pouca reserva existente na borbulha, o que acarreta em maior dificuldade de sobrevivência antes da união dos tecidos e, conseqüentemente, necessitando de um período mais longo para sua brotação e pegamento. Referente às gemas dormentes, as mesmas não estavam mortas, porém, o retardo de brotação em relação aos outros métodos é fator negativo pelo atraso da formação da nova copa, atrasando, assim, a futura produção precoce da nova cultivar (SIMÕES; CARVALHO, 2006). Por outro lado, Lederman et al. (1994) observaram que, em gravioleira, os métodos de borbulhia mostram superioridade quando comparados aos processos de garfagem.

As espécies por apresentam características morfofisiológicas diversas respondem de maneira diferente aos métodos de enxeria. Sabe-se que para garantir o sucesso da enxertia é necessário que haja conexão entre os tecidos próximos ao câmbio, que gera o calo ou cicatriz (PEIL, 2003). Essas diferenças em relação aos métodos de enxertia podem também estar relacionadas aos propágulos, já que os garfos possuem maior quantidade de reservas (carboidratos) em relação à borbulha, o que auxilia a cicatrização e brotação do enxerto (CELANT et al., 2010).

A porcentagem de brotação (BROT) apresentou 
efeito significativo na interação entre portaenxerto e métodos de enxertia (Tabela 4), verificando que a atemóia enxertada no araticum-do-brejo apresentou uma maior brotação em relação à atemóia enxertada na pinha. Entretanto, esse comportamento não foi verificado para os métodos de fenda cheia e borbulhia. No portaenxerto araticum-do-brejo, os métodos de enxertia inglês simples e fenda lateral apresentaram maior porcentagem de brotação em relação à inglês complicado, fenda cheia e borbulhia. Já no portaenxerto de pinha foi observado maior porcentagem de brotação para o método fenda lateral, porém os resultados foram semelhantes a todos os métodos com exceção da borbulhia.

Tabela 4. Percentagem de brotação do enxerto (BROT), percentagem de enxerto dormente (ED) e percentagem de pegamento (PEG) de mudas de atemoieira (Annona squamosa $\mathrm{x}$ Annona cherimola) em função do portaenxerto e do método de enxertia. Mossoró (RN), 2011.

\begin{tabular}{|c|c|c|c|c|c|c|}
\hline \multirow{3}{*}{ Enxertia* } & \multicolumn{2}{|c|}{ BROT (\%) } & \multicolumn{2}{|c|}{ ED (\%) } & \multicolumn{2}{|c|}{ PEG (\%) } \\
\hline & \multicolumn{6}{|c|}{ Portaenxerto } \\
\hline & Araticum & Pinha & Araticum & Pinha & Araticum & Pinha \\
\hline B & - & $3,33 \mathrm{~b}$ & - & $1,67 \mathrm{~b}$ & - & $8,33 \mathrm{c}$ \\
\hline $\mathrm{FC}$ & $6,67 \mathrm{~b} A$ & 6,67 a $A$ & - & $3,33 \mathrm{~b} \mathrm{~A}$ & 93,33 a A & 75,00 a B \\
\hline FL & 20,00 a $A$ & 8,33 a B & $3,33 \mathrm{~b}$ B & 10,00 a $A$ & 56,67 с A & $58,33 \mathrm{~b} \mathrm{~A}$ \\
\hline IC & $13,33 \mathrm{~b} \mathrm{~A}$ & 6,67 a $A$ & - & $3,33 \mathrm{~b} \mathrm{~A}$ & $76,67 \mathrm{~b} \mathrm{~A}$ & 83,33 a $A$ \\
\hline IS & $20,00 \mathrm{a} A$ & 6,67 a $B$ & 10,00 a $\mathrm{A}$ & $3,30 \mathrm{~b} \mathrm{~A}$ & $60,00 \mathrm{c} \mathrm{B}$ & 81,67 a $A$ \\
\hline
\end{tabular}

Nota: B-borbulhia; FC - fenda cheia; FL - fenda lateral; IC - inglesa complicada; IS - inglesa simples.

*Médias seguidas pela mesma letra, maiúscula na horizontal e minúscula na vertical, não diferem entre si pelo teste de Scott-Knott ao nível de $5 \%$ de probabilidade.

Fonte: Elaboração dos autores.

Para porcentagens de enxertos dormentes (ED) houve diferença significativa na interação (Tabela 1). Porém, conforme a Tabela 4, observou-se que as enxertias inglês simples para o araticum-dobrejo e fenda lateral para pinha apresentaram maior porcentagem de enxertos dormentes, 10\% para ambos.

Na variável pegamento(Tabela 4), o método fenda cheia apresentou um maior pegamento utilizandose o araticum-do-brejo como portaenxerto, sendo os pegamentos reduzidos nos demais métodos de enxertia. Ao utilizar a pinha como portaenxerto para atemoieira, os métodos inglês complicado, inglês simples e fenda cheia apresentaram maiores percentagens de pegamento diferindo das enxertias em fenda lateral e borbulhia que apresentaram resultados inferiores. Esse fato pode ser explicado pelo motivo da facilidade de junção dos câmbio do enxerto com o câmbio do portaenxerto nos métodos fenda cheia, inglês simples e inglês complicado.

As camadas exteriores expostas na região do câmbio, tanto do enxerto como do portaenxerto, produzem células parenquimáticas, que logo se misturam e entrelaçam, formando o que normalmente se denomina calo. No tecido caloso formado, algumas células que se encontram alinhadas com o câmbio intacto do enxerto e do portaenxerto, se diferenciam em novas células cambiais. Essas células produzem tecido vascular novo, xilema no interior e floema no exterior, o que é pré-requisito necessário para que a união das plantas tenha sucesso (HARTMANN et al., 2002).

A garfagem em inglês complicado é o método que atinge facilmente índices acima de 95\% de pegamento. O pegamento obtido neste trabalho para a enxertia inglês complicado foi de 76,67\% (araticum- 
do-brejo) e $83,33 \%$ (pinha). Porém se os enxertos brotados continuassem seus desenvolvimentos até a formação de mais folhas, bem como se as gemas dormentes dos garfos apresentassem também brotação, a porcentagem final de pegamento poderia atingir até 90\% (araticum-do-brejo) e 93,33\% (pinha), aproximando-se dos dados obtidos por Araújo e Castro Neto (2002) em experimento com umbuzeiro, obtendo média de $92,4 \%$.
O número de folhas é importante para avaliação do vigor induzido pelo portaenxerto. O portaenxerto pinha proporcionou maior número médio de folhas no enxerto com diferença significativa em relação ao araticum-do-brejo (Tabela 5). Ao enxertar a atemóia em araticum-de-terra-fria, Almeida (2009), obteve um número médio de 4,51 folhas no enxerto e 0,82 folhas quando o portaenxerto foi biriba, aos 60 dias após a enxertia.

Tabela 5. Diâmetro do colo (DC), comprimento da parte aérea (CPA) e número de folhas (NF) de mudas de atemoieira (Annona squamosa x Annona cherimola) em função do portaenxerto e do método de enxertia. Mossoró (RN), 2011.

\begin{tabular}{|c|c|c|c|c|c|c|}
\hline \multirow{3}{*}{ Enxertia* } & \multicolumn{2}{|c|}{ NF (unid. muda ${ }^{-1}$ ) } & \multicolumn{2}{|c|}{$\mathrm{CPA}(\mathrm{cm})$} & \multicolumn{2}{|c|}{$\mathrm{DC}(\mathrm{mm})$} \\
\hline & \multicolumn{6}{|c|}{ Portaenxerto } \\
\hline & Araticum & Pinha & Araticum & Pinha & Araticum & Pinha \\
\hline B & - & $1,99 \mathrm{c}$ & - & $6,44 \mathrm{c}$ & - & $3,39 \mathrm{~b}$ \\
\hline $\mathrm{FC}$ & 17,95 a A & 18,95 a A & 32,63 a $A$ & 33,83 a A & 6,63 a $A$ & 6,88 a A \\
\hline FL & 9,65 c B & $13,24 \mathrm{~b} \mathrm{~A}$ & 29,53 a $\mathrm{A}$ & $28,04 \mathrm{~b} \mathrm{~A}$ & 7,49 a $\mathrm{A}$ & 7,05 a A \\
\hline IC & 16,11 a B & 19,44 a A & 33,34 a $A$ & 33,82 a $A$ & 6,84 a A & 6,64 a A \\
\hline IS & 14,35 b B & 19,00 a $\mathrm{A}$ & 30,87 a $\mathrm{A}$ & 35,45 a A & 6,51 a A & 7,12 a A \\
\hline
\end{tabular}

Nota: B - borbulhia; FC - fenda cheia; FL - fenda lateral; IC - inglesa complicada; IS - inglesa simples.

*Médias seguidas pela mesma letra, maiúscula na vertical e minúscula na horizontal, não diferem entre si pelo teste de Scott-Knott ao nível de $5 \%$ de probabilidade.

Fonte: Elaboração dos autores.

O método de enxertia fenda cheia proporcionou maior número de folhas para o araticum-do-brejo e para a pinha, não diferindo estatisticamente entre os portaenxertos. Para o portaenxerto araticumdo-brejo, o método fenda cheia não diferiu do método inglês complicado, sendo superiores a inglês simples e fenda lateral. E para o portaenxerto pinha, o número de folhas dos métodos de enxertia fenda cheia, inglês complicado e inglês simples foram iguais, superando os métodos fenda lateral e borbulhia. Aos 60 dias após a enxertia, Almeida (2009) observou que o método de enxertia fenda lateral proporcionou maior número inicial de folhas com índice médio de 3,16 folhas. Resultado este bem diferente ao encontrado neste trabalho, que verificou que a fenda lateral apresentou resultados inferiores para ambos os portaenxertos, sendo os valores superiores apenas ao método de borbulhia.
Os resultados do número de folhas em função do método de enxertia estão de acordo com os encontrados por Souza, Botelho e Schreider (2007), para a cultura da videira, onde o método que se destacou foi a enxertia de fenda cheia. Góes (2011) estudando diferentes métodos de enxertia em tamarindeiro observou que o método garfagem em fenda lateral destacou-se por apresentar um menor número médio de folhas e que o maior número médio de folhas foi verificado nos métodos de enxertia em fenda cheia, à inglesa complicada e à inglesa simples, respectivamente.

O comprimento da parte aérea no portaenxerto pinha não apresentou diferença significativa em relação ao araticum-do-brejo. Porém houve diferença significativa entre os métodos de enxertia para o portaenxerto pinha, onde os métodos de enxertia inglês simples, fenda cheia e inglês 
complicado não diferiram entre si. Entretanto, apresentaram comprimento da parte aérea superiores aos métodos fenda lateral e borbulhia. Estes resultados corroboram com os encontrados por Góes (2011) para tamarindeiro, que observou maior crescimento da parte aérea quando realizada a enxertia através do método fenda cheia, inglês simples e inglês complicado, e que o método de garfagem lateral, apresentou comprimento da parte aérea inferior aos demais métodos. Vieira (2007) verificou que o comprimento da parte aérea de mudas de cupuaçuzeiro, quando realizadas as enxertias pelos métodos de garfagem no topo em fenda cheia e garfagem a inglês simples não apresentaram diferenças estatísticas entre si, embora as médias para a garfagem no topo em fenda cheia tenham sido ligeiramente superiores.

Resultados de trabalhos encontrados na literatura ratificam os que foram verificados neste trabalho, no qual se constatou que os métodos de garfagem apresentaram diferenças entre si, tendo se destacado entre eles o método garfagem em inglês simples, fenda cheia e inglês complicado, sendo superiores ao método de garfagem em fenda lateral e borbulhia para o portaenxerto pinha. Entretanto, para o portaenxerto araticum-do-brejo, não foi observado diferença estatística entre os métodos de enxertia estudados.

Tabela 6. Comprimento do sistema radicular (CSR), massa seca da parte aérea (MSPA) e massa seca do sistema radicular (MSSR) de mudas de atemoieira (Annona squamosa x Annona cherimola) em função do portaenxerto e do método de enxertia. Mossoró (RN), 2011.

\begin{tabular}{|c|c|c|c|c|c|c|}
\hline \multirow{3}{*}{ Enxertia* } & \multicolumn{2}{|c|}{ CSR $(\mathrm{cm})$} & \multicolumn{2}{|c|}{ MSPA $\left(\right.$ g muda $\left.^{-1}\right)$} & \multicolumn{2}{|c|}{$\operatorname{MSSR}\left(\mathrm{g} \mathrm{muda}^{-1}\right)$} \\
\hline & \multicolumn{6}{|c|}{ Portaenxerto } \\
\hline & Araticum & Pinha & Araticum & Pinha & Araticum & Pinha \\
\hline B & - & $19,12 \mathrm{~b}$ & - & $4,93 \mathrm{~b}$ & - & $1,93 \mathrm{c}$ \\
\hline $\mathrm{FC}$ & 49,63 a A & 46,10 a A & 3,89 a $\mathrm{B}$ & 7,45 a $\mathrm{A}$ & $2,50 \mathrm{~b} \mathrm{~A}$ & $2,88 \mathrm{~b} \mathrm{~A}$ \\
\hline FL & 49,42 a A & 42,56 a A & 4,20 a B & 7,83 a $A$ & 4,33 a $A$ & 3,70 a $A$ \\
\hline IC & 44,46 a A & 44,14 a A & 3,53 a B & 7,04 a A & 2,42 b A & $2,58 \mathrm{~b} \mathrm{~A}$ \\
\hline IS & 45,72 a A & 42,10 a A & 3,14 a B & 7,47 a A & $2,31 \mathrm{~b} \mathrm{~A}$ & $2,88 \mathrm{~b} \mathrm{~A}$ \\
\hline
\end{tabular}

Nota: B-borbulhia; FC- fenda cheia; FL-fenda lateral; IC-inglesa complicada; IS- inglesa simples.

*Médias seguidas pela mesma letra, maiúscula na horizontal e minúscula na vertical, não diferem entre si pelo teste de Scott-Knott ao nível de $5 \%$ de probabilidade.

Fonte: Elaboração dos autores. o diâmetro do colo, que não apresentaram diferença significativa entre os portaenxertos, porém verificouse uma diferença significativa entre os métodos de enxertia apenas para o portaenxerto de pinha, mostrando que a borbulhia apresentou um diâmetro do colo inferior aos demais métodos de enxertia.

De acordo com Celant et al. (2010) em cultivares de marmeleiro, o método de garfagem tipo fenda dupla proporciona maior comprimento e maior diâmetro médio dos enxertos, quando comparados aos propagados pelo método de borbulhia. O resultado corrobora os encontrados neste estudo, tendo em vista que houve diferença significativa apenas para o método de borbulhia. Gomes et al. (2010) verificaram, trabalhando com cajuí, que a característica diâmetro do portaenxerto apresenta diferença estatística entre todos os tipos de enxertia, sendo que o tipo fenda cheia apresentou maiores valores.

Os valores do comprimento do sistema radicular e da massa seca do sistema radicular não apresentaram diferença entre os portaenxertos (Tabela 6). No comprimento do sistema radicular, não houve diferença entre os métodos de enxertia para o portaenxerto araticum-do-brejo, mas, verificou-se uma diferença da borbulhia em relação aos demais métodos de enxertia no portaenxerto pinha, onde esta apresentou os menores resultados. 
A massa seca do sistema radicular apresentou diferença entre os métodos de enxertia nos dois portaenxertos. A garfagem em fenda lateral apresentou uma maior massa seca do sistema radicular $(4,33 \mathrm{~g} /$ planta $)$ para o portaenxerto araticum-do-brejo, diferindo dos outros métodos que apresentaram massa seca do sistema radicular variando de 2,31 a 2,50g/planta. E no portaenxerto pinha a enxertia fenda lateral também apresentou uma maior massa seca do sistema radicular $(3,70 \mathrm{~g} /$ planta), diferenciando dos demais métodos que apresentaram massa seca do sistema radicular variando de 1,93g/planta (borbulhia) a 2,88g/ planta (fenda cheia e inglês simples). Os resultados encontrados por Góes (2011) para tamarindeiros enxertados em tamarindeiros verificou-se que o método de enxertia fenda lateral apresentou uma maior massa seca do sistema radicular, corroborando com os resultados deste trabalho.

A massa seca da parte aérea apresentou resultados superiores para o portaenxerto pinha para todos os métodos de enxertia, com valores médios de 6,94 e 2,95g/planta para os portaenxertos de pinha e araticum-do-brejo, respectivamente. Entretanto, apenas o portaenxerto pinha apresentou diferença entre os métodos de enxertias, mostrando mais uma vez que a borbulhia apresenta os menores valores $(4,93 \mathrm{~g} / \mathrm{planta})$ quando comparado com os outros métodos de enxertia que não diferiram entre si, apresentando massa seca da parte aérea em um intervalo de 7,04 a 7,83g/planta (Tabela 6). De acordo com Ledo (1991), foi observado melhor desempenho de matéria seca em enxertos de diferentes variedades de graviola enxertadas na própria graviola pelo método inglês simples. De acordo com Ledo (1991) e Zenginbal, Ozcan e Demir (2007), o método inglês simples é superior quanto ao restabelecimento de vascularização entre enxerto e portaenxerto, constatando maior vigor de plantas enxertadas com o método inglês simples sobre o portaenxerto araticum-de-terra fria.

Na Tabela 7, pode-se verificar que a massa seca total e a relação massa seca da parte aérea e a massa seca do sistema radicular apresentaram diferença entre os portaenxertos, tendo o portaenxerto pinha a maior média da massa seca total $(9,74 \mathrm{~g} /$ planta) e da relação massa seca da parte aérea e a massa seca do sistema radicular $(2,22)$. Os valores médios da massa seca total e relação massa seca da parte aérea e a massa seca do sistema radicular para o portaenxerto araticum-do-brejo foram, respectivamente, 5,26g/ planta e 1,07 .

Tabela 7. Massa seca total (MST), comprimento da muda (CM) e a relação entre a massa seca da parte aérea e massa seca do sistema radicular de mudas de atemoieira (Annona squamosa x Annona cherimola) em função do portaenxerto e do método de enxertia. Mossoró (RN), 2011.

\begin{tabular}{|c|c|c|c|c|c|c|}
\hline \multirow{3}{*}{ Enxertia* } & \multicolumn{2}{|c|}{ MST $\left(\right.$ g muda $\left.^{-1}\right)$} & \multirow{2}{*}{\multicolumn{2}{|c|}{$\begin{array}{c}\mathrm{CM}(\mathrm{cm}) \\
\text { Portaenxerto }\end{array}$}} & \multicolumn{2}{|c|}{ MSPA/MSSR } \\
\hline & & & & & & \\
\hline & Araticum* & Pinha & Araticum & Pinha & Araticum & Pinha \\
\hline B & - & $6,87 \mathrm{~b}$ & - & $25,56 \mathrm{~b}$ & - & $1,05 \mathrm{~b}$ \\
\hline $\mathrm{FC}$ & 6,39 b B & 10,33 a A & 82,25 a A & 79,93 a A & $1,57 \mathrm{aB}$ & $2,62 \mathrm{aA}$ \\
\hline FL & 8,52 a B & 11,53 a A & 78,96 a A & 70,61 a A & $0,96 \mathrm{aB}$ & $2,11 \mathrm{aA}$ \\
\hline IC & 5,95 b B & 9,61 a A & 77,80 a A & 77,95 a A & $1,49 \mathrm{aB}$ & $2,72 \mathrm{aA}$ \\
\hline IS & 5,45 b B & 10,35 a A & 76,58 a A & 77,54 a A & $1,33 \mathrm{aB}$ & $2,60 \mathrm{aA}$ \\
\hline
\end{tabular}

Nota: B-borbulhia; FC- fenda cheia; FL-fenda lateral; IC-inglesa complicada; IS- inglesa simples.

*Médias seguidas pela mesma letra, maiúscula na horizontal e minúscula na vertical, não diferem entre si pelo teste de Scott-Knott ao nível de $5 \%$ de probabilidade.

Fonte: Elaboração dos autores. 
Para o portaenxerto araticum-do-brejo, a maior massa seca total foi de $8,52 \mathrm{~g} /$ planta para a enxertia fenda lateral, diferindo estatisticamente dos métodos inglês simples $(5,45 \mathrm{~g} /$ planta), inglês complicado $(5,95 \mathrm{~g} /$ planta $)$ e fenda cheia $(6,39 \mathrm{~g} /$ planta $)$. Porém, na relação entre a massa seca da parte aérea e a massa seca do sistema radicular não houve diferença entre os métodos de enxertia. Já no portaenxerto pinha, tanto a massa seca total como a relação entre a massa seca da parte aérea e a massa seca do sistema radicular diferiram entre os métodos de enxertia, sendo a borbulhia que apresentou os menores valores, $6,87 \mathrm{~g} /$ planta e 1,05, respectivamente. E os demais métodos não diferiram entre si nessas duas variáveis, sendo observados valores variando de 9,61 a 11,53 g/planta de massa seca total e de 2,11 a 2,72 para a relação entre a massa seca da parte aérea e a massa seca do sistema radicular.

O comprimento da muda $(\mathrm{CM})$ de atemóia não diferiu entre os portaenxertos, apresentando valores médios de $63,12 \mathrm{~cm}$ no portaenxerto araticum-dobrejo e $66,32 \mathrm{~cm}$ no portaenxerto pinha. Diferindo apenas entre os métodos de enxertia no portaenxerto pinha, sendo o menor valor e a única diferença para a borbulhia $(25,56 \mathrm{~cm})$ e os métodos fenda lateral, inglês simples, inglês complicado e fenda cheia obtiveram comprimento da muda de 70,61; 77,$54 ; 77,95$ e $79,93 \mathrm{~cm}$. Referente ao portaenxerto araticum-do-brejo, os comprimentos das mudas foram de $76,58 \mathrm{~cm}$ para o método inglês simples, $77,80 \mathrm{~cm}$ para o inglês complicado, $78,96 \mathrm{~cm}$ para fenda lateral e $82,25 \mathrm{~cm}$ para fenda cheia. Portanto, pode-se observar que as mudas para ambos portaenxertos apresentaram maiores valores para o método fenda cheia, mesmo não diferindo estatisticamente dos métodos fenda lateral, inglês simples e inglês complicado.

Os resultados obtidos no presente trabalho, nas condições de Mossoró/RN, demonstram que a enxertia de garfagem no topo em fenda cheia pode ser utilizada na produção de mudas de atemoieira de alta qualidade. Tendo em vista que, a utilização deste método de enxertia na propagação de atemoieira com os portaenxertos Annona glabra L. e Annona squamosa L. apresentaram melhor desenvolvimento das mudas aos 60 dias de idade.

\section{Conclusões}

A atemoieira 'Gefner' pode ser enxertadas nos portaenxertos Annona glabra L. e Annona squamosa L. pelo método de garfagem fenda cheia.

Os métodos de enxertia inglês simples e inglês complicado podem ser utilizados se a atemoieira 'Gefner' for enxertada no portaenxerto Annona squamosa L.

O método de enxertia por borbulhia não é eficiente para a produção de mudas de atemoieira 'Gefner'.

\section{Agradecimentos}

À Universidade Federal Rural do Semi-Árido pelos suportes técnico e científico oferecidos durante a realização deste trabalho.

Ao $\mathrm{CNPq}$, pelo apoio financeiro concedido durante todas as fases deste trabalho.

\section{Referências}

ALMEIDA, L. F. P. Propagação por enxertia de araticum (Annona crassiflora Mart.) e atemoia (Annona squamosa L. x Annona cherimola Mill.) em diferentes portaenxertos de Annonaceae. 2009. Dissertação (Mestrado em Fitotecnia) - Universidade de Brasília/Faculdade de Agronomia e Medicina Veterinária, Brasília.

ARAÚJO, F. P.; CASTRO NETO, M. T. Influência de fatores fisiológicos de plantas-matrizes e de épocas do ano no pegamento de diferentes métodos de enxertia do umbuzeiro. Revista Brasileira de Fruticultura, Jaboticabal, v. 24, n. 3, p. 752-755, dez. 2002.

BANZATTO, D. A.; KRONKA, S. N. Experimentação agrícola. Jaboticabal: FUNEP, 1989. 247 p.

CELANT, V. M.; PIO, R.; CHAGAS, E. A.; 
ALVARENGA, A. A.; DALASTRA, I. M.; CAMPAGNOLO, M. A. Armazenamento a frio de ramos porta-borbulhas e métodos de enxertia de cultivares de marmeleiro. Ciência Rural, Santa Maria, v. 40, n. 1, p. 1-5, jan./fev. 2010.

FREITAS, G. B. Propagação, florescimento, frutificação e produção da gravioleira (Annona muricata L.). 1997. Tese (Doutorado em Fitotecnia) - Universidade Federal de Viçosa, Viçosa, MG.

GÓES, G. B. de. Propagação do tamarindeiro (Tamarindus indica L.) e da pitombeira (Talisia esculenta Raldk) por enxertia. 2011. Dissertação (Mestrado em Fitotecnia: Fruticultura) - Pró-Reitoria de PósGraduação. Universidade Federal Rural do Semi-Árido, Mossoró.

GOMES, J. G.; OLIVEIRA, N. C. C.; LOPES, P. S. N.; CARNEIRO, P. A. P.; Enxertia do cajuí (Anacardium othonianum Rizz.) no Norte de Minas Gerais. In: CONGRESSO BRASILEIRO DE FRUTICULTURA. 21., 2010, Natal. Anais... Natal: Sociedade Brasileira de Fruticultura. 2010. p. 18-0283.

HARTMANN, H. T. KESTER, D. E.; DAVIES, F. T.; GENEVE, R. L. Plant propagation: principles and practices. $7^{\text {th }}$ ed. Upper SaddleRiver: Prentice Hall, 2002. 849 p.

KAVATI, R. O cultivo da atemóia. In: DONADIO, L. C.; MARTINS, A. B. G.; VALENTE, J. P. Fruticultura tropical. Jaboticabal: FUNEP, 1992. p. 39-70.

LEDERMAN, I. E.; SILVA, M. F. F. da; BEZERRA, J. E. F.; PEDROSA, A. C. Influência da idade do portaenxerto e do tipo de enxertia na propagação da gravioleira (Annona muricata) In: CONGRESSO BRASILEIRO DE FRUTICULTURA, 13., 1994. Salvador. Anais... Salvador, BA: SBF, 1994, v. 2, p. 593-594.

LEDO, A. Resposta de três gravioleiras (Annona muricata L.) a dois métodos de enxertia. 1991. Dissertação (Mestrado em Fitotecnia) - Universidade Federal de Viçosa, Viçosa, MG.

PADMAJA, V.; THANKAMANY, V.; HARA, N.;
FUJIMOTO, Y.; HISHAM, A. Biological activities of Annona glabra. Journal of Ethnopharmacology, Clare, v. 48, n. 1, p. 21-24, aug. 1995.

PEIL, R. M. A enxertia na produção de mudas de hortaliças. Ciência Rural, Santa Maria, v. 33, n. 6, p. 1169-1177, 2003.

ROCHA, A. M. M. R.; ARAÚJO, J. F.; ROCHA, E. M. M.; VIANNA, M. C. Influência de diferentes substratos no desenvolvimento de mudas de pinheira (Annona squamosa L.). In: CONGRESSO BRASILEIRO DE FRUTICULTURA, 17., 2002, Belém. Resumos... Belém: EMBRAPA/SBF, 2002. 1CD-ROM.

SIMÕES, F.; CARVALHO, R. I. N. Avaliação de diferentes métodos de sobre-enxertia na substituição da cultivar de macieira (Malus domestica Borkh.) Gala por Princesa. Acta Scientia Agronômica, Maringá, v. 28, n. 4, p. 493-498, out./dez. 2006.

SOUZA, J.; BOTELHO, R. V.; SCHREIDER, E. avaliação dos métodos e épocas de enxertia em videira 'niagara rosada' (Vitis labrusca) sobre o portaenxerto '43-43' (V. Vinifera XV. rotundifolia). In: ENCONTRO PARANAENSE DE FRUTICULTURA, 2007, Guarapuava. Anais... Guarapuava: UNICENTRO, 2007. p. 124-125.

TOKUNAGA, T. A cultura da atemóia. Campinas: CATI, 2000. $80 \mathrm{p}$.

VIEIRA, E. S. Propagação vegetativa do cupuaçuzeiro por enxertia e estaquia. 2007. Dissertação (Mestrado em Fitotecnia) - Centro de Ciências Agrárias Ambientais e Biológicas. Universidade Federal do Recôncavo da Bahia, Cruz das Almas.

ZENGINBAL, H.; OZCAN, A. H.; DEMIR, T. Comparisons of methods and time of budaling in Kiwifruit (Actinidia deliciosa, A. Chev.) International Journal Natural Engineering Sciences, Turkey, v. 1, n. 1, p. 23-28, 2007. 
